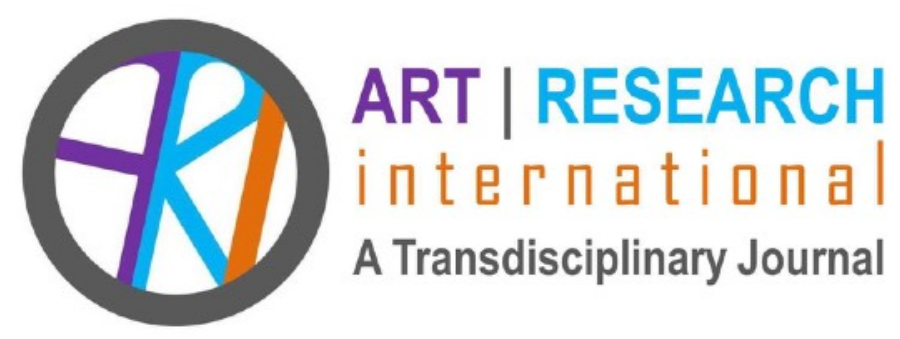

\title{
PAINTING FROM THE OTHER SIDE: TRACING THE REPARATIVE TURN IN CONTEMPORARY PRACTICE
}

\author{
Shannon Forrester \\ Royal College of Art (RCA) \\ Shannon.Forrester@network.rca.ac.uk
}

Shannon Forrester is an international artist working in the expanded field of painting and interdisciplinary practice-led research. Forrester is a $\mathrm{PhD}$ candidate at the Royal College of Art, School of Arts and Humanities in the Fine Art Research Program currently working on developing reparative-turn theory in painting and practice. Forrester has a BFA from School of the Art Institute of Chicago, an MFA Painting and Graduate Certificate in Women's, Gender, and Sexuality Studies (WGS) from Boston University. Their interdisciplinary work incorporates painting, curation, and writing at the intersection of WGS, new materialism, colour philosophy, and cultural studies. Forrester also works in faculty roles in the US and UK. Shannon's work and exhibitions in the US, UK, and India have been featured in Two Coats of Paint, APlus, Hindustan Times, and BostonVoyager. Forrester's paintings have been selected for inclusion in exhibitions and galleries of international scope such as collateral project at Kochi-Muziris Biennale, a solo exhibition at VOLTA NY, and at A.I.R. Gallery in Brooklyn, NY. Forrester regularly presents new research at a wide array of academic events in the US, UK, and Europe.

Abstract: Painting from the Other Side, is the curatorial project section of a larger interdisciplinary practice-led research project titled Embodying the Reparative Turn: Seeking Agency through Studio Practice in Individual and Collective Contexts that investigates the potential of the reparative turn in painting, aesthetics, narrative, and curation to subvert, evade, and exit from dynamics of exclusion linked to homophobia, misogyny, and racism. It considers how systemic cultural agents propagating exclusion deploy inequity to obstruct human flourishing, then explores how they are subverted through diverse reparative practices in painting. Painting from the Other Side included an open call for paintings that engage with reparative content by artists whose identities are in some way outside of the minority power position of the Western canon of painting by straight white male artists. It 
included intensive studio visits and culminated in an exhibition. This paper proposes a theoretical framework of reparative painting and practice, tracing the many paths researchparticipant artists followed towards a reparative turn in painting.

Keywords: contemporary painting; feminism; reparative; social justice; curation; hopeful futurity; human flourishing 
As we critically imagine new ways to think and write about visual art, as we make spaces for dialog across boundaries, we engage a process of cultural transformation that will ultimately create a revolution in vision - bell hooks ${ }^{1}$

The power of visual interventions to produce culture is well known, yet research examining the affective power (as related to both painter and viewer) of painting within a specifically reparative framework remains greatly unconsidered. This paper will focus on Painting from the Other Side, which was the curatorial project section of a larger interdisciplinary practice-led research project titled Embodying the Reparative Turn: Seeking Agency through Studio Practice in Individual and Collective Contexts that examines this question. It investigates the potential of the reparative turn in painting, aesthetics, narrative, and curation to subvert, evade, and exit from dynamics of exclusion linked to homophobia, misogyny, and racism. It considers how systemic cultural agents that propagate exclusion deploy inequity to obstruct human flourishing, then explores how these agents are subverted through diverse reparative practices in painting. Painting from the Other Side included an open call for paintings that engage with reparative content by artists whose identities are in some way outside of the minority power position of the western canon of painting by straight white male artists. The research included intensive studio visits between the participant artists who responded to the open call and me in the role of curator as well as researcher and painter. The studio visits allowed participant artists to discuss their work in depth, and provided an opportunity to outline the scope of the overall research project in development and reparative turn theory in painting. The research for Painting from the Other Side was conducted between fall 2018 and 2019. This paper focuses on presenting reparative turn theory in painting and tracing the highly diverse paths participant artists explored in the context of reparative painting. The research process allowed for in depth discussion between emerging contemporary painters who felt their work in some way intersected with reparative intention and/or ambition(s), presenting painting within a reparative framework while tracing its many tributaries, then culminated in an exhibition held 2-7 April, 2019 at Royal College of Art Dyson Gallery, London, and this paper.

\section{On the Dynamic Reparative Lens}

The reparative painting theory proposed here is not about a medium or style; it is a way of seeing, a way of thinking, an intention, a hunger, and also, in Painting from the Other Side, an action traced in painting through curating, looking, writing, reading, and making.

Reparative theory can be traced back to some of the psychoanalytic work of Melanie Klein which influenced "Paranoid Reading and Reparative Reading" by Eve Kosofsky Sedgwick. ${ }^{2}$ The work of these scholars was informative to Reparative Aesthetics by Susan Best which focused on photography and Cruising Utopia by Jose Estéban Muñoz a book that explores queer utopia(s). ${ }^{3}$ These texts inform much of the theoretical framework for both Embodying the Reparative Turn and Painting from the Other Side. 
Especially since the civil rights movements in the US (e.g. March on Washington in 1963, the Stonewall riot in 1969 and the Equal Rights Amendment Marches in 1972), fields of identity studies in North America have engaged in expansive analysis of these systems through critical paranoid-based reading approaches which are often characterized by an aim to expose the methods and aims of oppression. A reparative turn offers a constructive action, a re-making-inventing of an empowered-self narrative, an undertaking of a kind of surgery on wounds inflicted by systemic oppression, producing a hopeful exit from othering's shadows in the context of a creative imaginary engaged with the many possible new existence(s) repair might produce. Halberstam and Nyong'o would refer to the site of the repaired, or what exists after an exit, as "wildness," Muñoz would describe it as a queer utopia, hooks might say that the path to these places is through art. ${ }^{4}$ Additionally, new materialist theory offered by Barad, Coole and Frost, and Golding puts forth a new vision of a materially active dynamic world in infinite interactive becomings and its relationship to the socio-political realm, offering another wave through which to diffract these ideas of agency and the ambition to exit. 5

The concept of reparative is usually placed in relationship to a paranoid approach, which in many ways expects the worst so as to avoid surprise (which according to Sedgwick is assumed to be bad.) Sedgewick offers her framing of the reparative turn in the following passage which is highly relevant to Painting from the Other Side and specific to the "sustenance" of reparative dynamics found in culture, even when that culture is hostile and discriminatory. This passage also references the significant gap in knowledge related to critical reparative thought especially in feminist and queer theory. Additionally, it offers hope in terms of how the reparative approach might foster development of new methodologies and positions that contest dynamics of exclusion:

The vocabulary for articulating any reader's reparative motive toward a text or a culture has long been so sappy, aestheticizing, defensive, anti-intellectual, or reactionary that it's no wonder few critics are willing to describe their acquaintance with such motives. The prohibitive problem, however, has been in the limitations of present theoretical vocabularies rather than in the reparative motive itself. No less acute than a paranoid position, no less realistic, no less attached to a project of survival, and neither less nor more delusional or fantasmatic, the reparative reading position undertakes a different range of affects, ambitions, and risks. What we can best learn from such practices are, perhaps, the many ways selves and communities succeed in extracting sustenance from the objects of a culture-even of a culture whose avowed desire has often been not to sustain them. 6 (emphasis mine)

In Reparative Aesthetics Best uses Sedgewick's concept of reparative and practices as a lens to analyze the predominant identity politics position in contemporary art describing it as anti-aesthetic, a reveal of the known, and a "paranoid reading."7 Best positions reparative aesthetics in art as something that instead "holds negative and positive together, seeks 
pleasure rather than avoidance of shame as a reparative, and has a capacity to assimilate violence."8

In "Paranoid Reading and Reparative Reading" Sedgwick explains how Klein's psychoanalytic theories inform her paranoid/reparative "reading" practices and in some ways incorporate depression (as an anxiety mitigating exit from the relentlessness of the paranoid as well as in its relationship with guilt which is often operated as a possible guard against the subjects "more destructive influences") as well as love:9

The greatest interest of Klein's concept lies, it seems to me in her seeing the paranoid position always in the oscillatory context of a very different possible one: the depressive position. For Klein's infant or adult, the paranoid position - understandably marked by hatred, envy, and anxiety - is a position of terrible alertness to the dangers posed by the hateful and envious part - objects that one defensively projects onto, carves out of, and ingests from the world around one. By contrast, the depressive position is an anxiety-mitigating achievement that the infant or adult only sometimes and often only briefly, succeeds in inhabiting: this is the position from which it is possible in turn to use one's own resources to assemble or "repair" the murderous part-objects into something like a whole - though, I would emphasize, not necessarily like any preexisting whole. Once assembled to one's own specifications, the more satisfying object is available both to be identified with and to offer one nourishment and comfort in turn. Among Klein's names for the reparative process is love. ${ }^{10}$

To further examine Klein's description of depression, in Introduction to Melanie Klein, Segal explains that "The pain of mourning experienced in the depressive position, and the reparative drives developed to restore the loved internal and external objects, are the basis of creativity and sublimation." 11 So then, it is the desire to repair the pain of the paranoid that exists in the depressive position which links the reparative and depressive.

The reparative turn is not medium specific, art specific, or genre specific. It is not a style, a fad, or a dynamic with limited potential. It is a type of reading, not as "reading" per se, but as in something to experience/see/think/understand/consider through. It is an action, perhaps a lens for the mind, a reaching desire to repair something and make it better. It offers a conceptual framework which one can look, think, and in the case of Embodying the Reparative Turn and Painting from the Other Side, also make through. Critically, the reparative turn examined here implies a movement towards an exit. An exit through which issues related to marginalization based on race, gender, and sexuality bias, will find some aspect of repair as well as an implied, and/or clear, reaching towards something better. For those drawn to reparative work, their ambition is often driven by a hunger. This hunger is often linked to a desire to subvert wrongs, heal pain (psychic, emotional, physical,) exact revenge against and/or express/expose pain related to oppression, generate beauty, peace, joy and/or something that will improve things for themselves and/or others. The reparative is 
anchored to the subject's position and (in the case of this project) their personal psychoemotional as well as socio-political context, desires, hopes, and experiences.

The reparative functions in multivalent and multifaceted ways. It is always in a relative encounter with its partner subject(s)/context(s) who, in the case of Painting from the Other Side, are the artists, the paintings, and/or the audience viewers. So then, the reparative turn is also a relativity-based dynamic capable of great dexterity, change, and affect that is defined/produced/experienced by a painting, its creator, and/or it's audience. The reparative turn in painting is not a fixed or flat paradigm but a field behaving in ways similar to how Barad describes quantum field theory (QFT) in Meeting the Universe Halfway "According to quantum field theory, the vacuum is far from empty; indeed, it's teeming with the full set of possibilities of what may come to be..."12 We can also trace the primacy of reparative function/action through the interests of designers in their approach to creating new technologies that act as automated entities (AI), extensions and/or prosthetics of their human(s) which can be programmed to serve, control, in some cases replace and/or direct humans. In a discussion about the ethics of techno scientific practices and Al, Barad offers a quote by a National Science Foundation officer who was testifying to the US congress as to the relevance of $\mathrm{QFT}$ :

Viewing cells as computational devices will help enable the design of next generation computers that feature self organization, self repair, and adaptive characteristics that we see in biological systems. - NSF TESTIMONY TO CONGRESS, March 1, 200013

It is significant that the NSF only offered three characteristics to describe what the next generation of "quantum computing" computational cellular devices would "feature," and all of those qualities are directly related to the structure of reparative artistic praxis as well as being apparent in biological systems. This is not meant to infer that painting is exactly Al, but it is a type of intelligence. Reparative painting is self-organized, by the artist who organizes their concept in a highly adaptive relationship with its context, the material, form, and colour into a dynamic assemblage output resulting in a painting that has aliveness and affective reparative impact (see here Isabelle Graw The Love of Painting.) ${ }^{14}$ Further, Barads concept of performative discursive practice also speaks to the nature of the dynamic assemblage that is reparative painting:

A performative understanding of discursive practices challenges the representationalist belief in the power of words to represent preexisting things. Performativity, properly construed, is not an invitation to turn everything (including material bodies) into words; on the contrary, performativity is precisely a contestation of the excessive power granted to language to determine what is real. ${ }^{15}$

The reparative turn in painting is far beyond language; it is about repair of self and/or others. It is highly adaptive, always relative to its maker, context, and viewer. 
By including new materialism in the framework of reparative painting theory as proposed here, I argue that new materialism itself offers a type of reparative turn. New materialist scholarship reaches toward a dynamic, responsive, field of being instead of a binary either/or that has been the predominant (in many ways paranoid reading-based) structure informing progressive social liberation-oriented theory (especially queer, feminist, and intersectional theory) for the last few decades. Coole and Frost provide a succinct map of how new materialist scholars explain the crucialness of considering connections between politics, nature, and its bodies:

For new materialists, no adequate political theory can ignore the importance of bodies in situating empirical actors within a material environment of nature, other bodies, and the socioeconomic structures that dictate where and how they find sustenance, satisfy their desires, or obtain the resources necessary for participating in political life. ${ }^{16}$

These ideas of matter and its mattering, of multiplicity, describe how the material world, its bodies and environments in assemblage, can be considered in new dynamic ways. ${ }^{17}$ It is through these ideas from physics related to the dynamics of matter and materiality that the potential impact of new materialism on reparative painting theory begins to take shape. It offers a type of ever active relational-relativity framework that seeks to consider dynamics from the atomic to the socio-political and how the atomic can offer a (new) material case against paradigms of subjugation. Barad's conception of nature as itself being filled with queer imaginings is a clear example of these ideas. ${ }^{18}$ Critical to painting is Barad's foregrounding of the agency of matter: "Matter is an imaginative material exploration of non/ being, creatively regenerative, an ongoing trans*/formation. Matter is a condensation of dispersed and multiple beings-times, where the future and past are diffracted into now, into each moment." 19 It is easy to read this passage and think the text could refer to both making and looking at painting. In "Transmaterialities: Trans*/Matter/Realities and Queer Political Imaginings," Barad places the political and cultural dynamics of social liberation, creativity, a call for an imaginative approach to materiality, considerations about time, all of their complexities and more on a conceptual dance floor together, turns on the music then sets them in motion explaining that:

This is an experimental piece with a political investment in creating new political imaginaries and new understandings of imagining in its materiality. Not imaginaries of some future or elsewhere to arrive at or be achieved as a political goal but, rather, imaginaries with material existences...imaginaries that are attuned to the condensations of past and future condensed into each moment; imaginaries that entail superpositions of many beings and times, multiple im/possibilities that coexist and are iteratively intra-actively reconfigured; imaginaries that are material explorations of the mutual indeterminacies of being and time. ${ }^{20}$ 
Reparative painting, in fact painting itself, is an artform with an essence grounded in mobilizing particulate, elemental, materials in fatty suspension, into projections of healing, empowerment, expression, rage, and much more. Painting seems to personify new materialism in unique and unexpected ways. Perhaps it is its character, so tied to the natural world (materially, visually, and theoretically,) that makes painting and new materialism close relations. Surely, it is also the ability of painting to time travel and produce new political imaginaries through its materiality.

\section{Painting from the Other Side, an Encounter}

As research for Embodying the Reparative Turn: Seeking Agency through Studio Practice in Individual and Collective Contexts progressed, it became clear that discerning the reparative turn in paintings by other artists using close looking alone was an approach limited in numerous aspects. Artists thoughts are not transparently elucidated in their entirety in their final distillation as paintings. Deeper layers of meaning, ideas, and the paths artists took to arrive at the painting are likely inaccessible (partially or completely) to viewers through looking alone. Hidden in the creative process of painting are the building blocks that led up to its creation, this path of formation offers a map to the reparative turn in many of the works discussed in the following. Additionally, the nature of the visual realm, its creation of meaning, affect, and content, especially in painting engaged with intense subject matter, is usually multivalent and complex. What painting and visuality can do conveys meaning and creates encounters differently than text-based language (it is productive here to again think of Barad's thoughts on performative discursive practice), offering a physical/material experience that lends itself to affective dimensions in different ways than text. ${ }^{21}$ For example, that people and paintings exist materially in shared space, offers a significantly different encounter than engaging with text-based language which exists as sign-based content (usually) on the flat surface of paper or a screen. Further, I argue (along with Isabelle Graw) that painting works as not just an object, but also as a subject or as subject like object/entity. ${ }^{22}$

This dynamic of intellect and/or subjective aliveness in painting is multifaceted, as the painting itself is a physical manifestation of the artist's creation as well as their immaterial self. Additionally, paintings offer not just a physical presence in their materiality, but also in the colour-figure-ground-compositional elements that exist on the picture plane. This quote from Graw about colour brings the aliveness and potential of painting into focus, crediting the power of colour and its material identity as nature:

Color seems to me to have been predestined for this task thanks to pigment's inherent relation to nature. Pigments are harvested from nature and thus come with an immanent aspect of life and self-agency. In addition, the corporeality of pigments, their connection to the material world, is apt in creating the impression of life. ${ }^{23}$ 
When a painting is seen, these elements of colour, nature, materiality, seem in motion as they reach toward becoming. As a result, an encounter with painting has great potential to generate an affective response in viewers and painters alike. Human like, paintings incorporate the mark of the painter's hand, raw materials of nature, figures, colour, etc. In essence, they become a complex human output imbued with matter and its aliveness. In the framework of this project, the affective dimensions at play in an encounter with painting, especially in terms of its potential to produce agency as a means of an exit from identitybased marginalization, are critical to the genesis of a reparative turn. In Visualizing Feeling Best provides a productive description of the relationship between affective dynamics and art saying that, "The affective dimension is a feature of both subject and object. Put very simply, this can be phrased as 'when a work of art is moving, I am moved' - affect permeates the aesthetic encounter."24

\section{Tracing Reparative Painting in the Studio Wilds 25}

The curatorial, research-participant artist interviews, and exhibition facets of Painting from the Other Side were developed to allow the form of the larger practice-led research project (and development of reparative turn theory in painting) to materialize beyond personal painting practice, expanding it to include conversation with other contemporary painters. A highly diverse set of approaches to reparative painting were uncovered in the essays/images submitted during the application process and discovered during the studio interviews. Each research participant artist pursued different trajectories into the reparative, ultimately exposing a multitude of previously unimagined productions of reparative painting, exhibiting the productive ever-in-motion chameleon-like character of this framework. The connections between the often deeply personal topics this project addressed, the hunger for repair, the ambition to exit from dynamics of bias, and the profound dynamic relationship between painter and painting were pivotal to fleshing out the theory of reparative painting presented here.

The first round of studio visits with research participant artists were completed in January 2019. Each visit lasted approximately one hour, allowing time for general discussion regarding the planned overall research process for Painting from the Other Side, explanation of the exhibition theme, discussion about their applications to the open call, and painting practices. The concept of reparative painting and how their work might demonstrate a reparative turn produced interesting as well as productive realizations for both participant artists and researcher. During the studio visits, many research-participant artists conveyed both their interest in the idea of reparative painting and their confusion about it. Some shared their frustration that, in preparation for their application and later the studio visit, their search for more information about reparative painting provided no answers because there is no available knowledge about reparative painting theory. This pointed to a clear gap in knowledge and scholarship in this topic. 
For the research participants who grasped a sense of reparative painting without being able to find references in painting theory, there were some who expressed their position that within the context of the canon of Western painting, after so many centuries of exclusion, just becoming painters and making paintings was reparative in itself. Which of course is true, because for those who were excluded from art because of their identity, being able to enter previously forbidden spaces (in this case the space of the painter which in the historical canon of great Western painters was nearly exclusively a club for straight, white, Christian men) would surely be one of the first requirements to repair their sense of belonging in the field of painting. It was, however, those artists who were, not just entering the previously (nearly) inaccessible space of painting, but those artists whose work additionally grappled with concepts of reparative painting related to issues of gender, race, and sexuality, that offered the most interesting contributions to the research.

Their work took many reparative routes; some used aesthetic approaches to subvert socially inflicted identity-based uglying, others transformed the everyday instruments of colonial power by taking them into their own hands, wielding them with their own power. Others appropriated patriarchy's abjectification of women's bodies by disempowering toxic masculinity with male bodies. Through painting, some exposed what they had closeted by celebrating gay sexuality, using preciousness and gold leaf as indexes of desire which internalized homophobia had previously forbidden them to express.

\section{Reparative Turn Through Aesthetics and Beauty}

The artists included in this section, Kate Bickmore, Shannon Forrester and Jhonatan Pulido, submitted work that gave significant consideration to aesthetics and beauty as a feature of their specific reparative turn in painting. Using rich colour and imagery to generate an affective reparative encounter, the artists, while producing politically charged work, found beauty a key method to convey those reparative aims. The choice to produce socially engaged work which is aesthetically beautiful, is not the common approach to political art. Much like Sedgwick's theories about the dominance of the paranoid approach to identity studies, historically, political art has used a similar approach. I would suggest that like "reparative reading practice," beauty is thought of as lacking the kind of hard-hitting qualities required to meaningfully engage with political subject matter of this nature. Whereas, more "paranoid" approaches committed to exposure and critique of wrongs, seem to excel. Best suggests that artists using aesthetics and beauty to produce socially engaged art,

...make a radical break with the dominant anti-aesthetic approaches to political art. The anti-aesthetic tradition privileges critique over aesthetic engagement and rejects the importance of traditional aesthetic concerns such as beauty, feeling, expression and judgement. In contrast, these artists use a range of complex aesthetic strategies to engage audiences with these histories and to temper, at times transform, the feelings of shame that would normally accompany them. ${ }^{26}$ 


\section{Artist Kate Bickmore ${ }^{27}$}

Five pictures from Bickmore's current series of floral and foliage paintings exploring ideas of lesbian desire, the gaze, aesthetics, and asserting her agency in the realm of painting within the context of patriarchy, were submitted to the open call. Her work also played on, as well as sought to subvert, the female stereotypes featured in a significant percentage of paintings in the canon (see muses, nudes, objectified women etc.) The botanical paintings foregrounded flowers as central figures surrounded by lush foliage together serving as indexical icons which, combined with the titles of the paintings, conjure women, their bodies, their desires, troubling how the canon of Western painting has portrayed and objectified them. Bickmore's work also intervenes in tradition's trope of woman as the flower-object target of male lust/sexuality by usurping its familiar visual language and replacing the common pedestrian patriarchal lens of heterosexual desire with lesbian desire.

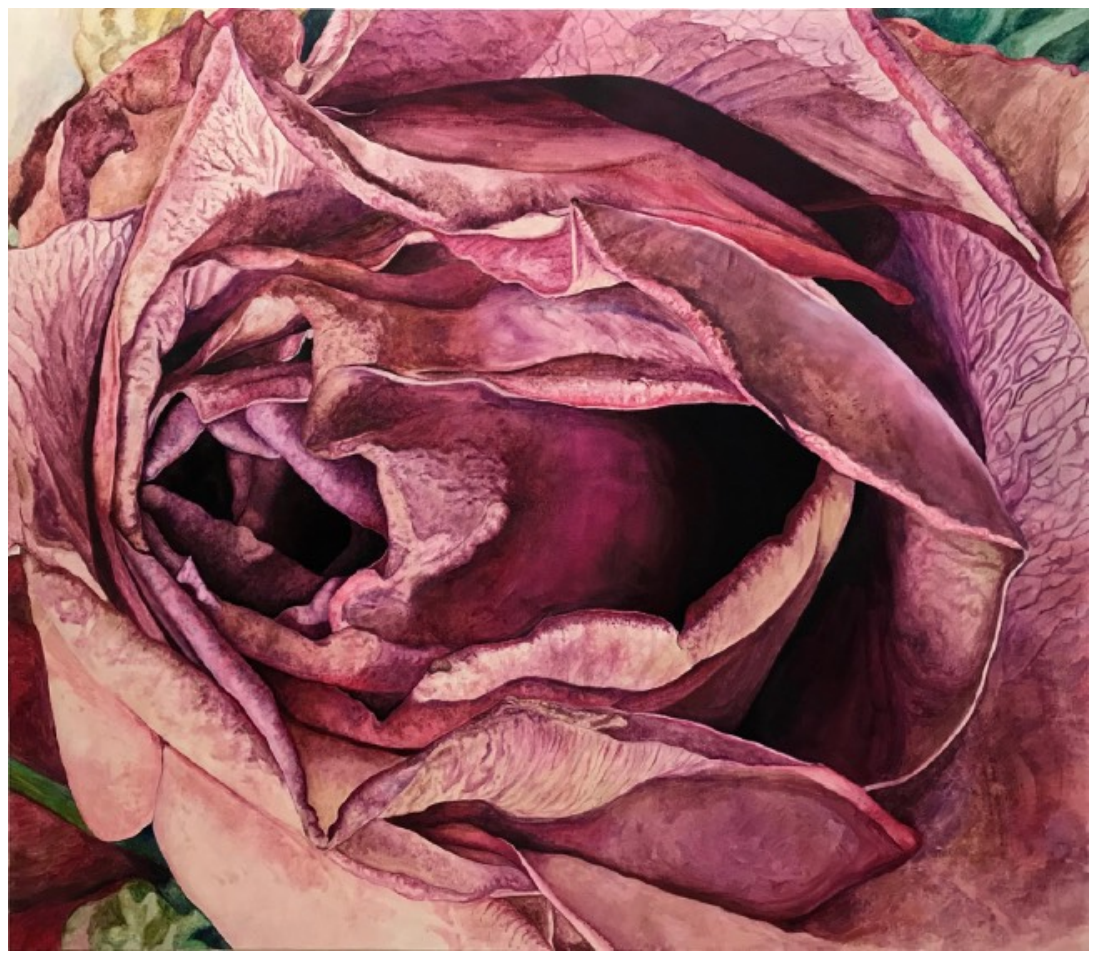

Figure 1. Kate Bickmore, Climbing Out of Her Sheets, 132 x $152 \mathrm{~cm}$, oil on canvas, 2019

Climbing out of her Sheets has an undeniable reparative power. Its visual position converges aesthetic beauty, desire, a loving, as well as humorous, ode to lesbian sexuality, and the vagina (which patriarchy loves to legislate, make invisible, control, render dirty, dominate, and often abuse.) Western culture teaches women from a young age their bodies are less than male, that they represent a lacking, an absence, that vaginas are abject, 
unclean. Yet, in Climbing out of Her Sheets, Bickmore offers a lusciously painted rose, an iconic sign of love, then combines that meaning with the culturally abject vagina and lesbian sexuality. The effect of this triadic visual move subverts patriarchy's attempt to disparagingly define women, their bodies, and their sexuality, placing the positioning power to define women's bodies instead with women, in this case with Bickmore, but I would argue also with the viewer. To see such a visceral physical human aspect and vibrant dedication to lesbian sexuality, both of which are so commonly marginalized and monsterized in culture, lovingly revered creates room for a deeply affective, as well as reparative impact, especially for those afflicted by misogynistic and homophobic bias. Bickmore described this series as having an aim to "... reinvent a canonized depiction of women and nature by reacting to the patriarchal constraints imposed upon painting by the male gaze."28

\section{Artist Shannon Forrester29}

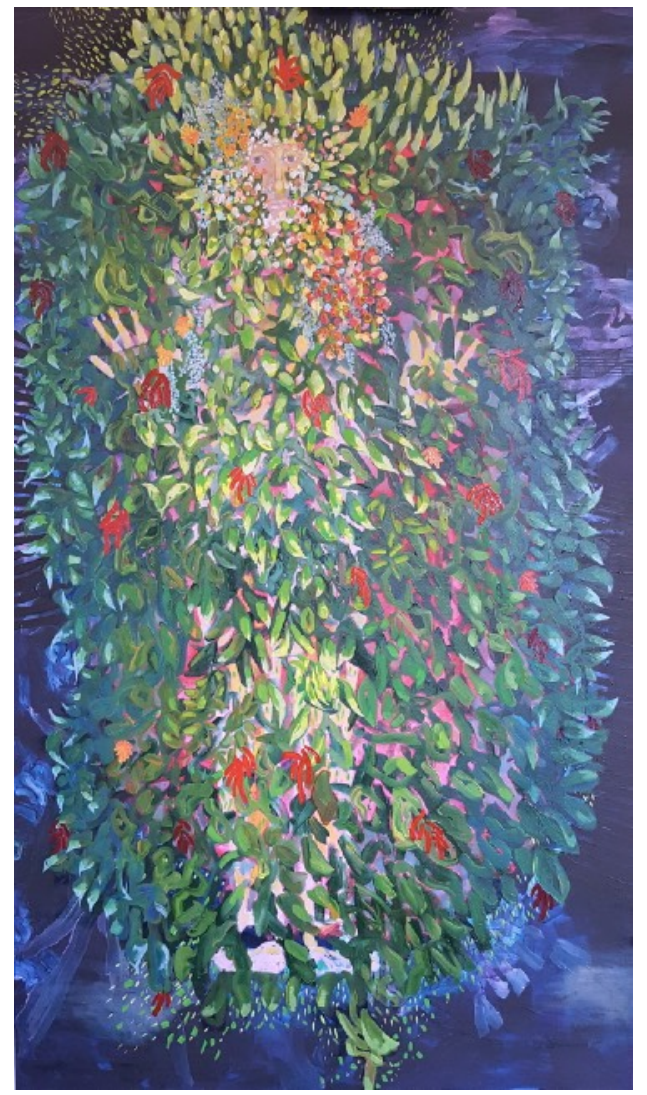

Figure 2. Shannon Forrester, Begin, $6 \mathrm{ft} \mathrm{h} \times 45$ in w, oil on canvas, 2018

Begin, a painting from my own practice-led artistic research, which in its full form includes a poetic element, was also exhibited in Painting from the Other Side. The poetic element was a step outside of painting while still engaged with creating in the context of transmutation; this step allowed me to additionally explore concept translation into narrative 
and creative text. Findings in these modes of translation became most interesting when a similar concept was used to make both a painting and a creative text. Surprising synergies emerged between the three sites of production (concept, painting, creative text).

Begin first entered the research as a painting; it was not until later that I realized it was connected to an experimental poetic text I subsequently completed. Within the scope of this research, it was interesting to explore the relationships between these very different research outputs, especially when artistic research usually commits to spanning both forms. The poetic element, Begin, follows.

\section{Begin}

There was no light, dirt (another being) covered the small human figure, a bestowal from Patriarchy's Workshop to function as a public broadcast of her shame, her name, her meaning made embodied, that which is a marker of her abject caste. Built on in layers with every unfolding year, though she was only about seven, the coating was material, aural, visceral, and seemingly all powerful, though she could not even see it. A droning, relentless transmission of psychic and physical excruciation, It enveloped with mercenary mastery. Its thick-heavy volume weighed upon every flicker of her material and immaterial being. As a captive of Patriarchy's Workshop, she was conscripted to carry it as her outermost layer, her most prominent identifier, this embodied dirt-other had travelled with her during every moment of her life so far.

To spite constructed appearance, It was not actually of her but on her, a permeable layer fiction-being-signifier forged with all the ill intent the Workshop could construct. The immensity of shame, of droning transmissions, began eroding her spirit from the moment she began to be conscious of the socio-political. That was when it came home to roost, commencing its parasitical dance of nightmares on her frame. The process began years before the layers weighing her down were so thick. It is constitutively productive in its complex and ingenious character. It was a spark born from darkness that allowed her story to be told, as The Workshop's corrosive agent was meant to silence her, render her forever without light. The Workshop didn't understand the power of no-light, as within it, the little captive could drift through the immense field of her mind and there she found truth, escape, seeds, and matches. 30

\section{Artist Jhonatan Pulido31}

Pulido submitted five paintings to the open call from his Rural Republic series. The collection of new paintings was inspired by his first childhood memories of paint and the vibrant aesthetic mise-en-scène of the countryside neighbourhood in Colombia where he grew up. The landscape of buildings in his hometown was a veritable visual feast of colour in which each building made its own vibrant addition. It included seemingly endless hues that 
unfurled across a landscape scale concert of diverse colour-interaction. The Rural Republic series not only portrays the architecture of colour in his hometown, it also explores the deeply fraught history of violence that stains it, a story that ultimately unfolded in blood and paint.

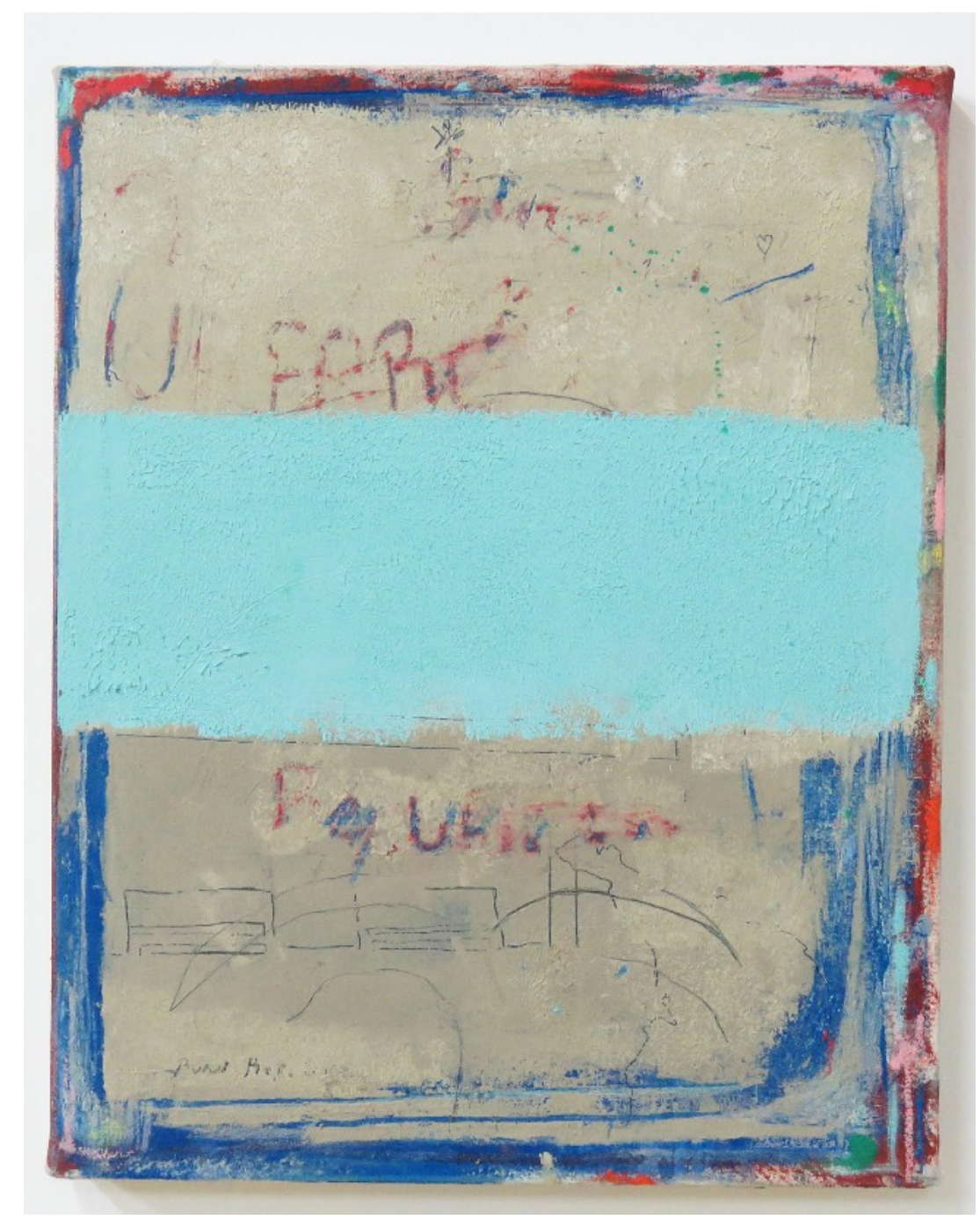

Figure 3. Jhonatan Pulido, Rural Republic, oil on canvas, 52 x 42 cm, 2018

The idea for the series was sparked by a complex early childhood memory related to and activated by painting, the public sphere, the forbidden, and the exposed. As all of this multifaced content became activated in his studio. Pulido had a significant realization that great painting, its power, its story, does not only exist in the iconic galleries dedicated to the canon of Western art. Paint, he realized, did important work right there in his remote, very rural hometown - a place that, for a time, was plagued by frequent violence between 


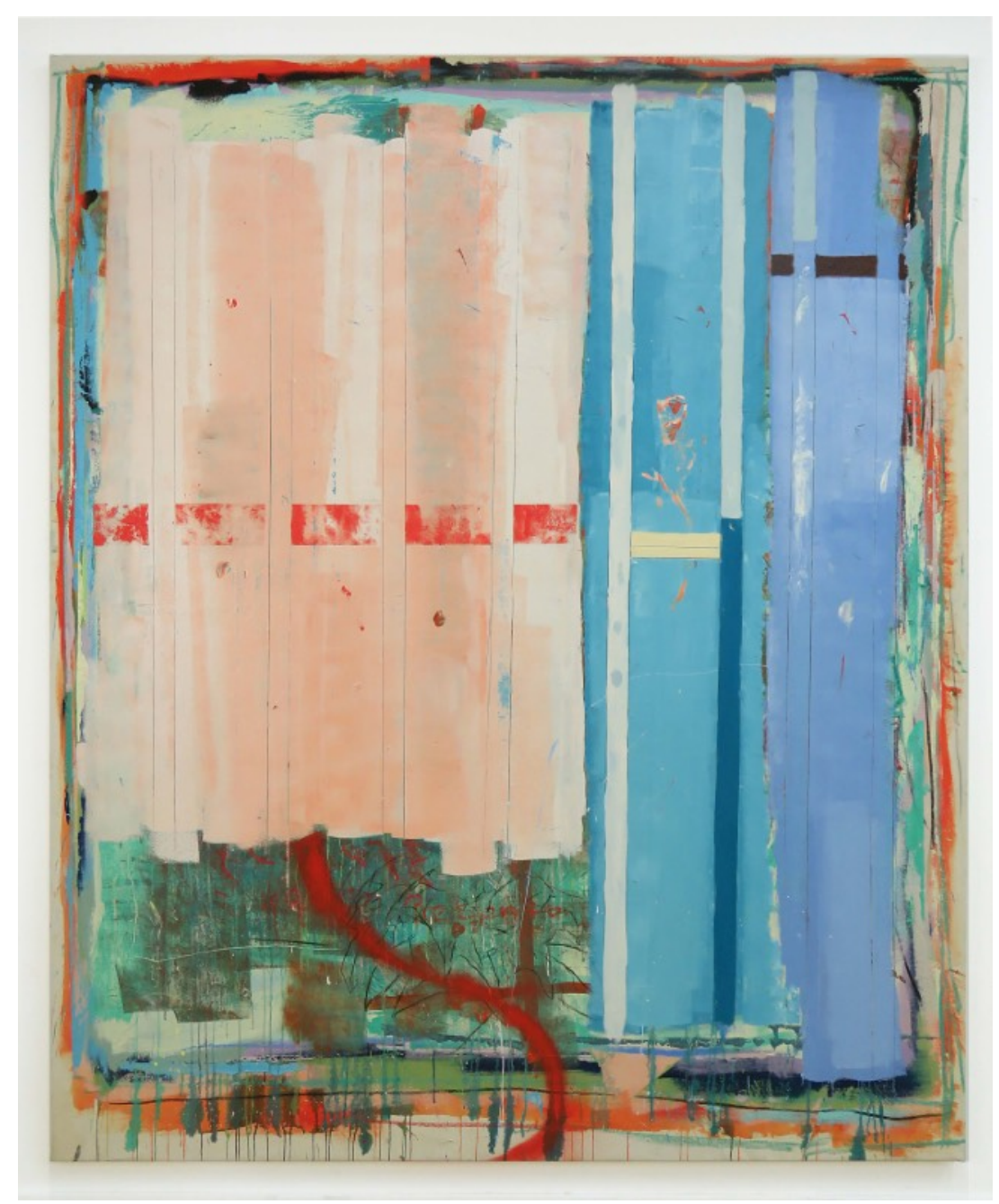

Figure 4. Jhonatan Pulido, Portrait of a weapon, oil on canvas, $225 \times 188 \mathrm{~cm}, 2019$

government agents and local rebels fighting against them. The murders and bloodshed were very real, but they were also carried out in ways that were in some repects hidden. It did not look like a "war zone" because much of the fabric of the violent operation was covert. The dark reality of that time was in stark contrast to such a beautiful setting overflowing with complex vibrant colour. Pulido's Rural Republic series operates in a way described by Henrik Kaare Nielsen in his article Discursive Interventions which explores aesthetics and the political:

When art intervenes into politics, it happens via the cultural public sphere, where art by way of its specific formal and thematic tools creates "odd" new insights and ways of experiencing, and on this basis offers its own, specific space of reflection as a mirror to other discursive fields, including the political. ${ }^{32}$ 
One aspect of the turmoil that was not hidden, was the painting, which in some respects unfolded as a war of words and colours. Each side painted messages, slogans, and claims against the other. Government agents called for compliance, rebels called for freedom, progressively painting over and erasing each other's last painting. Their sociopolitical battle unfolded in the public realm through a combination of violence, intimidation, fear, and paint. In this war, paint became a human agent with a voice, a power, and a call for cultural change inserted onto the surface of the bucolic buildings of that countryside, while it also served as an agent of the oppressive government. The paint was so powerful, it struck fear in the population, they always erased it when it appeared, painting over the battle messages with swatches of new lush solid colour.

This remarkable story of painting has a multitude of reparative actions. We could first consider this use of paint as a way to materially refute political violence and oppression by physically erasing messages that marred the landscape, attempting to return the countryside to a setting of beauty, colour, and safety. Painting was a vehicle for the rebels' cause and it repaired some aspect of the inequitable power relations between the rebel and government agents by giving them the power of a platform from which they could conduct their fight against oppression through mass communication in paint.

Additionally, the moment of Pulido's realization that great painting happened not just within the hallowed halls of the Western canon, but that it happened right there, in rural Colombia, where paint was heroic, visceral, hypnotic, powerful, affective, important, and alive, offers a richly complex reparative turn that validated his own painting. Close looking at Pulido's abstracted paintings reveals the essence of these childhood encounters with paint, the socio-political, as well as the cultural production of belief. The layering, erasing, repainting, scraping, pastel colour palette all have a major presence in the series. Rural Republic offers a unique contribution to the canon of reparative painting in the ways it addresses activist aesthetics, social justice, and a critically imperative expansion of the meaning of great painting that moves its borders beyond the historic confines of the limited scope of stereotypic white male master painters from the Western canon.

\section{Reparative Turn Through Therapeutic Autobiography}

\section{Artist Lydia Pettit33}

Pettit submitted four highly personal paintings to the open call. The story about them conveyed in her application text made clear how critical painting is for her as a vehicle to reparatively think, imagine, and work through past trauma, as well as everyday life as a woman trying to find ways to survive life subjected to a patriarchal social system. Like many examples of strongly compelling reparative painting, Pettit's pictures offer multiple reparative aspects. Interruption for example includes a dual self-portrait, picturing the artist primarily in transparency, mist, and reflection. The instance of her portrayal in a more flesh-like 


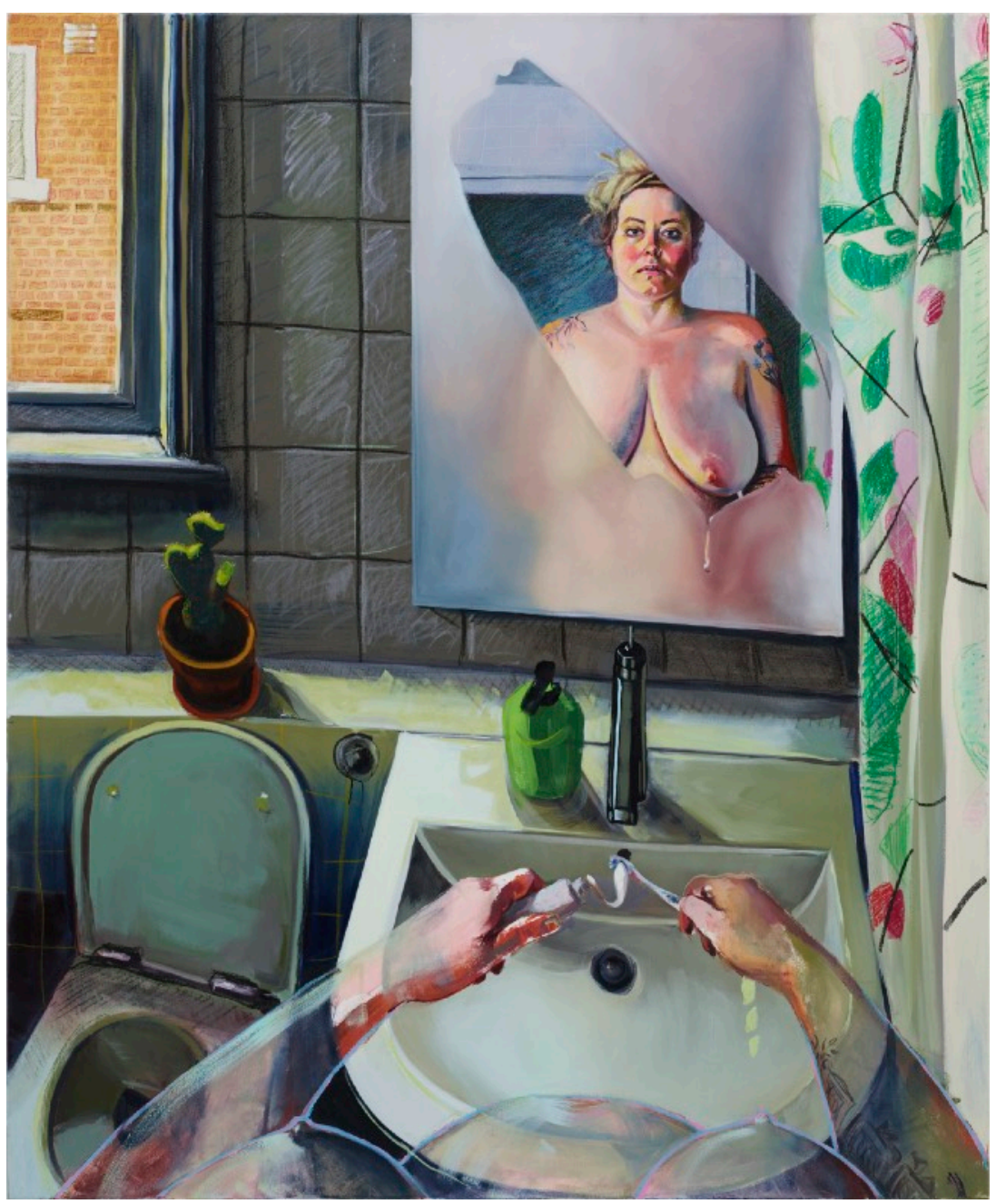

Figure 5. Lydia Pettit, Interruption, oil and oil pastel on canvas, $140 \times 170 \mathrm{~cm}, 2018$

embodiment only occurs in the very small section of her hands engaged in the beginning stage of cleaning her teeth. The painting switches worlds in a mist of bathroom haze between a figure ghost, a figure obscured, and a figure cleaning itself.

Loaded in this image are traces of cyclical feelings of shame/hiding, exposure, and nakedness of truth that the artist struggles with as a survivor of physical and emotional abuse by men. Her paintings give her a platform of strength from which she can work through these feelings for her own wellbeing while also making them visible to other women who are survivors - providing them with a psychic-visual space to work through similar issues and/or find recognition, validation, and understanding. In these ways, her paintings allow other survivors, even if they cannot paint, to benefit from this record of Pettit's struggles to cope with trauma. As a result, her paintings have an affective healing dimension for the artist, and seek to repair feelings of trauma, isolation and shame survivors often suffer. Through the visual language of Interruption, Pettit exposes the narrative of a survivor 
whose path towards recovery is heroic and reparative in its truth, bravery, and raw confrontation with the damaging affective dimensions of trauma.

\section{Artist Elise Broadway ${ }^{34}$}

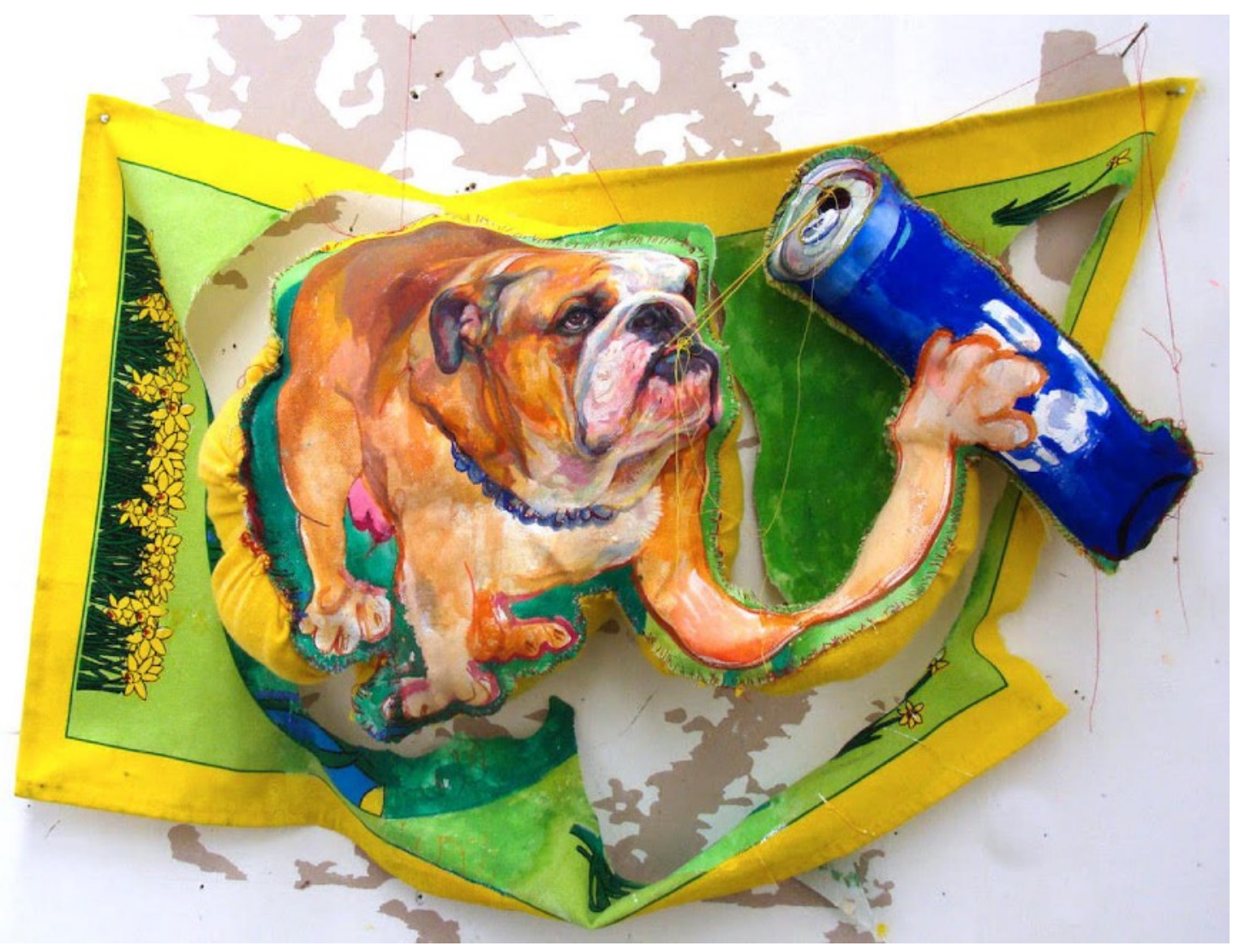

Figure 6. Elise Broadway, Good Boy, gauche and mixed media, $45 \times 60 \times 20 \mathrm{~cm}, 2018$

Broadway applied to the open call with three pieces, two sculptural paintings and one two-dimensional painting. Her work navigates autobiography at the intersection of race, gender, sexuality, kinship, and mental health in the context of the American southwest. Broadway had difficult kinship relationships growing up as many family members were proud of their supposed ancestral links to Robert E. Lee and the civil war era southern confederacy. They also embraced extremist religious conservatism paired with its requisite homophobia and misogyny. Growing up in this kinship network and the wider social context of the American south created a dynamic of ongoing emotional and psychological turbulence for Broadway. Some of Broadway's paintings become a record of her search for images that she can use to construct an attempt to work through, conceive of, and reveal the truth about the racist, homophobic, and misogynistic values which stain the culture of the American south. Her paintings also capture her work to find and express a narrative that seeks to 


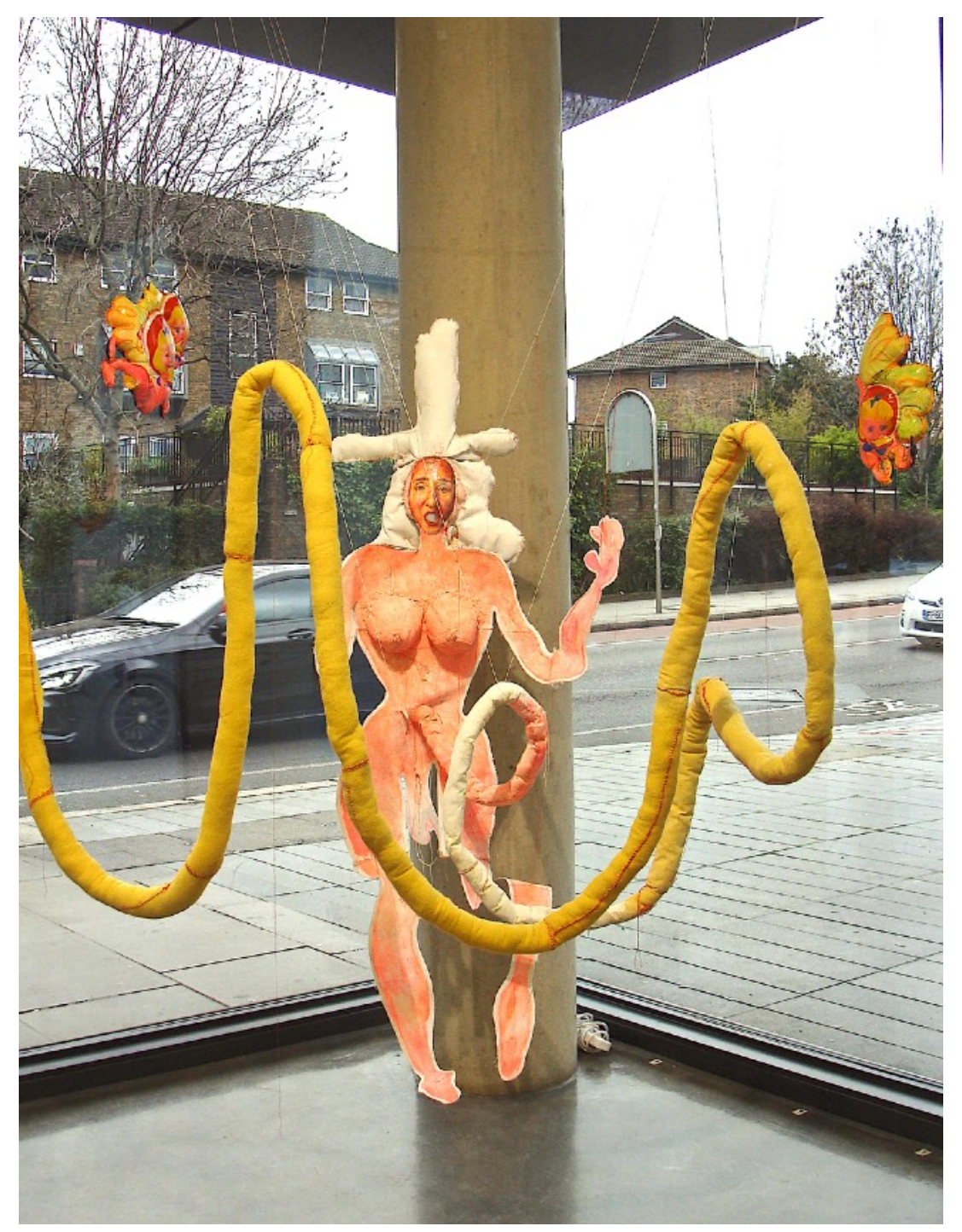

Figure 7. Elise Broadway, Blow Up, $140 \times 60 \times 182 \mathrm{~cm}$ (varies by installation), gouache, gesso, and thread (hand-sewn) on cotton dish towels and yellow dusters, armature wire and polyester stuffing, 2018-19

reveal a truth and somehow heal the complex damages that type of hate inflicts on a young LGBT woman who survived girlhood in its shadow.

In Good Boy, Broadway works at unravelling the stereotype of the strong heroic white southern American man who was glorified as an ideal human by the cultural beliefs of her kinship network, which served as key agents of the rejection and marginalization she faced. The sculptural painting removed his humanity, replacing him with a dog whose anatomy is grotesquely distorted. The bulldog often seems badly inbred, overweight for its size, suffering from joint problems, visibly struggling to breathe or even walk normally. The 
physical lacking of the bulldog points to the declining health endemic in her kinship network, while also unravelling the mirage of the heroic white southern man.

The dog emerges from a cut up destroyed landscape, a portrait painted with a hot pink scrotum, ensuring there is no question as to the sex of the animal. It also seems drunk, if not already drunk, it is at least on its way, drinking an XL Bud Light in what seems a familiar and comfortable regular habit. This dog stand-in is a proposal that there is no idyllic strong white southern "real" American hero-man, demonstrating how that trope is steeped in sickening toxic masculinity, in actuality inbred, barely mobile, and drunk. The reparative turn in Good Boy is found in its ability to expose the fallacy of that toxic white masculinity by laying bare its lack - subverting the stereotype by removing the heroic all-powerful position of its persona, replacing it with the truth that it is more like a sick inbred drunk. Good Boy is a coup d'état seeking to remove the myth which serves to generate power for the white southern American patriarch by using a play from his own book. Broadway dethrones the stereotype by establishing the lacking and dysfunction of his body just as patriarchy has done to women for generations.

\section{Reparative Turn Through Celebrating What was Closeted}

\section{Artist Leon Pozniakow35}
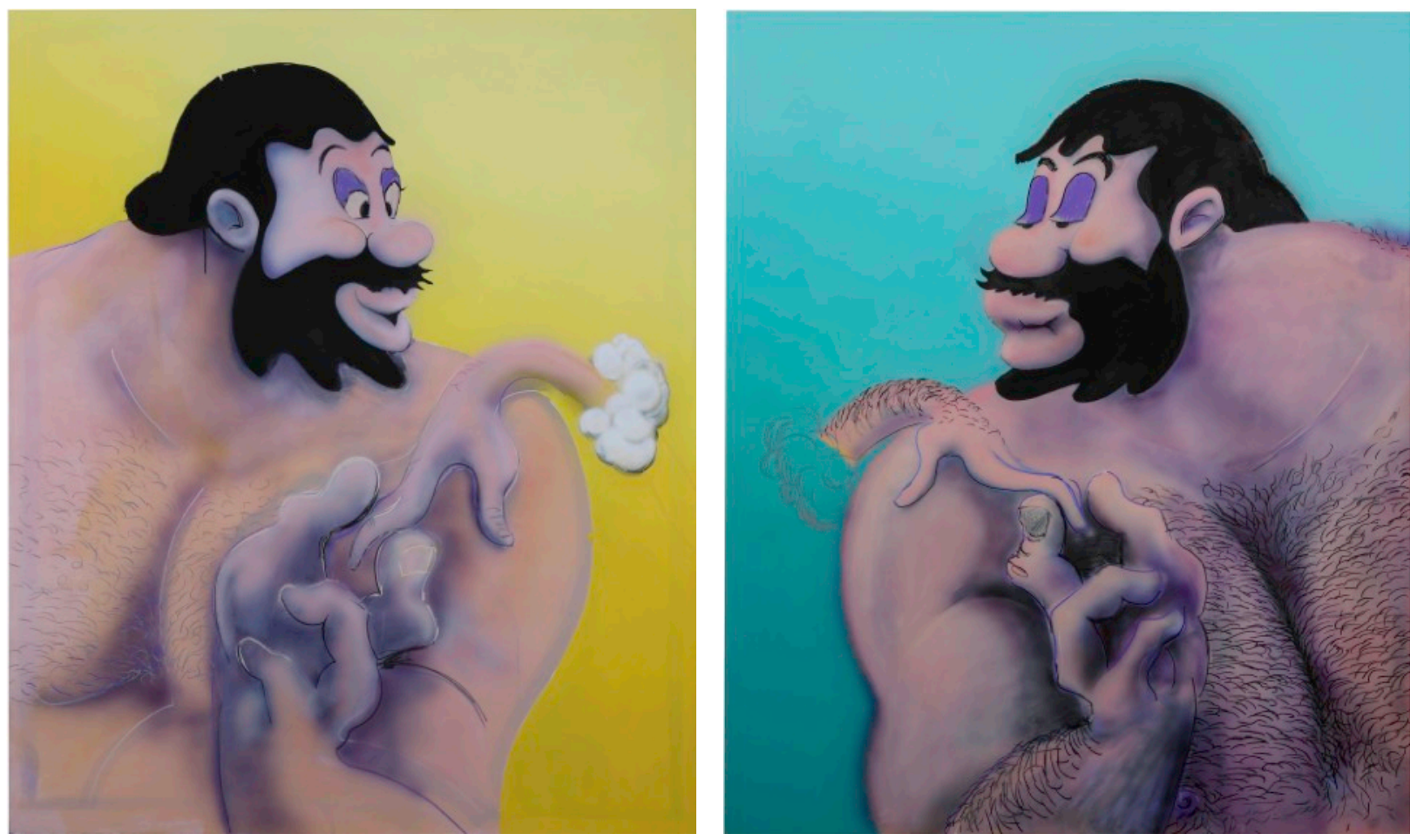

Figure 8. Leon Pozniakow, In Absence of the Man I Loved $A$ and In Absence of the Man I Loved B, oil and acrylic on Linen, 2019 (diptych) 
Pozniakow applied to the open call with a collection of five paintings of visual erotic longings for the bearish male body that he says explore the "gayverse" - a concept he works with that encompasses interior thoughts/desires and the exterior social context using figurative as well as materially specific (such as gold leaf) passages. In spite of their erotic yearnings, the paintings retain some dimension of fraught juxtaposition between celebratory desire and echoes of homophobia's shame, a toxic intervention in thoughts and feelings that plagued him much of his adult life. In his application text, Pozniakow wrote of this dynamic in his work saying that the paintings are "drawing inspiration from the sublime and the shadowy, enticing with fetishized representations of male beauty that both honour and disturb the body." 36 For context, it could be productive to look towards Best again here to

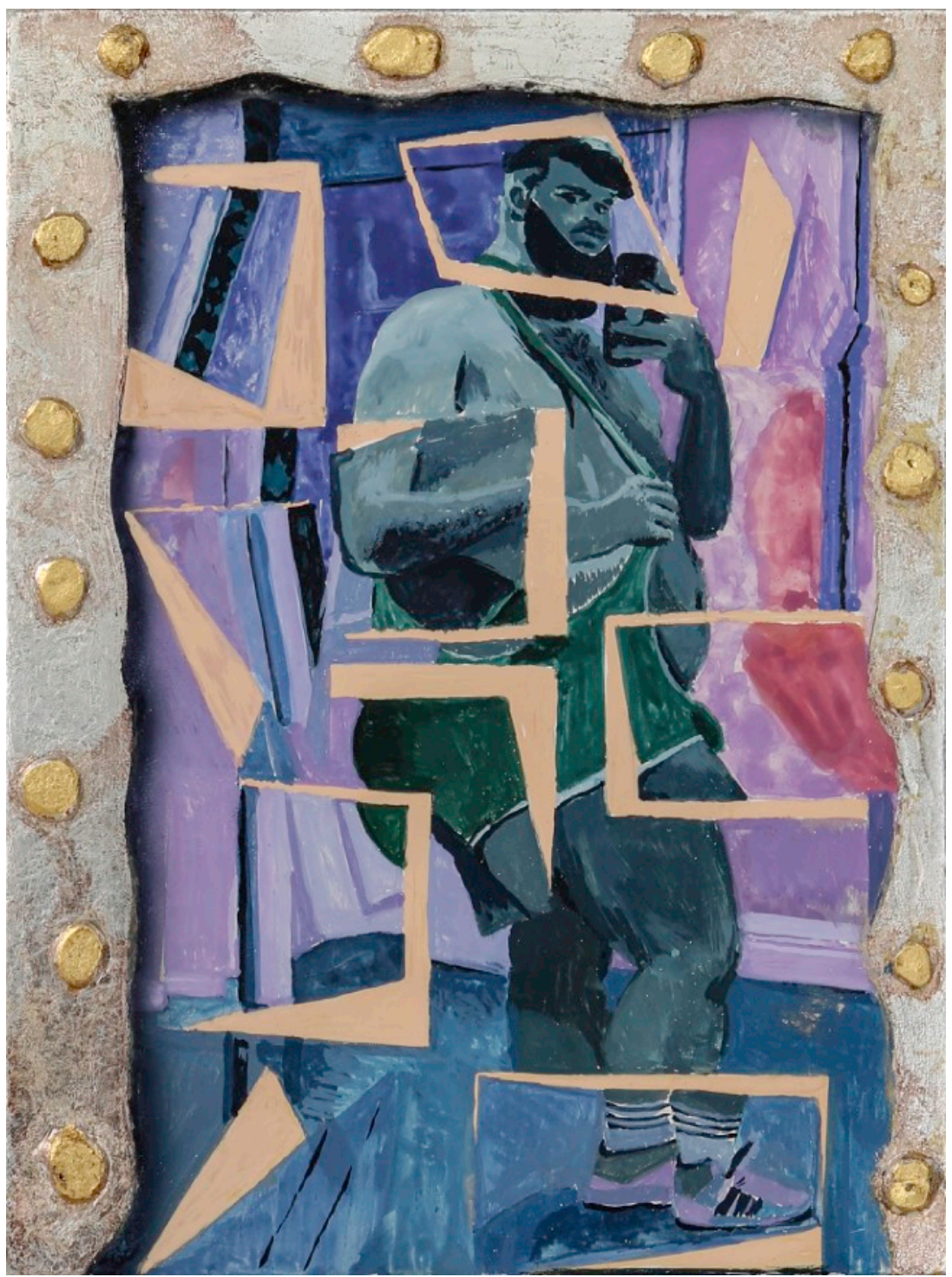

Figure 9. Leon Pozniakow, The Collector, watercolour, silver and gold leaf on panel, $15 \mathrm{~cm}$ x $20 \mathrm{~cm}, 2018$ 
help further conceptualize the possibility of repair by way of difficult content and the reparative dimension's drive to assimilate violence in order to achieve repair.

In the paintings, he celebrates the beauty of the bear and his desire for it. Pozniakow often paints people he interacts with through internet-fed screens, that he sees in cartoons, and/or in comics. He began painting these figurative narratives after experiencing censorship at a conservative art institution. Realizing the impact of the painful psychological affects that experience had on him, combined with the pain of being closeted about his sexuality for most of his life, his paintings took a reparative turn towards this new narrative grounded in pride and desire, firmly positioned outside of the closet. The paintings open the door on the closet that used to hide him. They become a platform for Pozniakow to make visible what shame tried in vain to erase. They help free him (as well as others trapped in the closet, struggling with similar issues of shame) to be, and show the true self.

\section{Reparative Turn Through Reclamation of Colonial Objects of Power and Elevation of Everyday Materials}

Hence, if the task is to unfix and loosen up dichotomous codifications of difference, the terrain within which black artists intervene can no longer be adequately met by an aesthetics of realism or protest which seeks to counteract "misrepresentation," but requires an acknowledgement of the emotional reality of fantasy as the domain of psychic life that is also subject to the demands of the unconscious. - Kobena Mercer37

\section{Artist Osaretin Ugiagbe 38}

Ugiagbe applied to the exhibition with five painted mixed-media collages that focused on a few key ideas he was working through in the studio. I will focus here on what seemed a key assemblage of topics: his experiences growing up in Nigeria, as a foreigner in the United Kingdom, an immigrant in the United States, the importance of everyday material, and power dynamics of educational settings. Living in the United Kingdom seemed to have brought many aspects of his life in post-colonial Nigeria to front of mind for Ugiagbe. Living suddenly in the heart of imperial power, perhaps the traces of its nefarious colonial history in Africa, became visible to him in new ways. Considering his life, at the time, working as a graduate student within a British institution, perhaps pedagogy and education were also not surprising topics to find emerging in his paintings. 1234 stood out as a significant reparative turn in painting, because its narrative was grounded in family, power, the impact of the postcolonial pedagogical authority of educators and its impact on students.

During the studio visit, Ugiagbe talked in detail about the importance of material choice in his paintings and his interest in exploring the power of materially, refuting the canon of great Western painting by integrating everyday material into his work instead of using more traditional oil paint and working on stretched canvas. In effect, these choices 


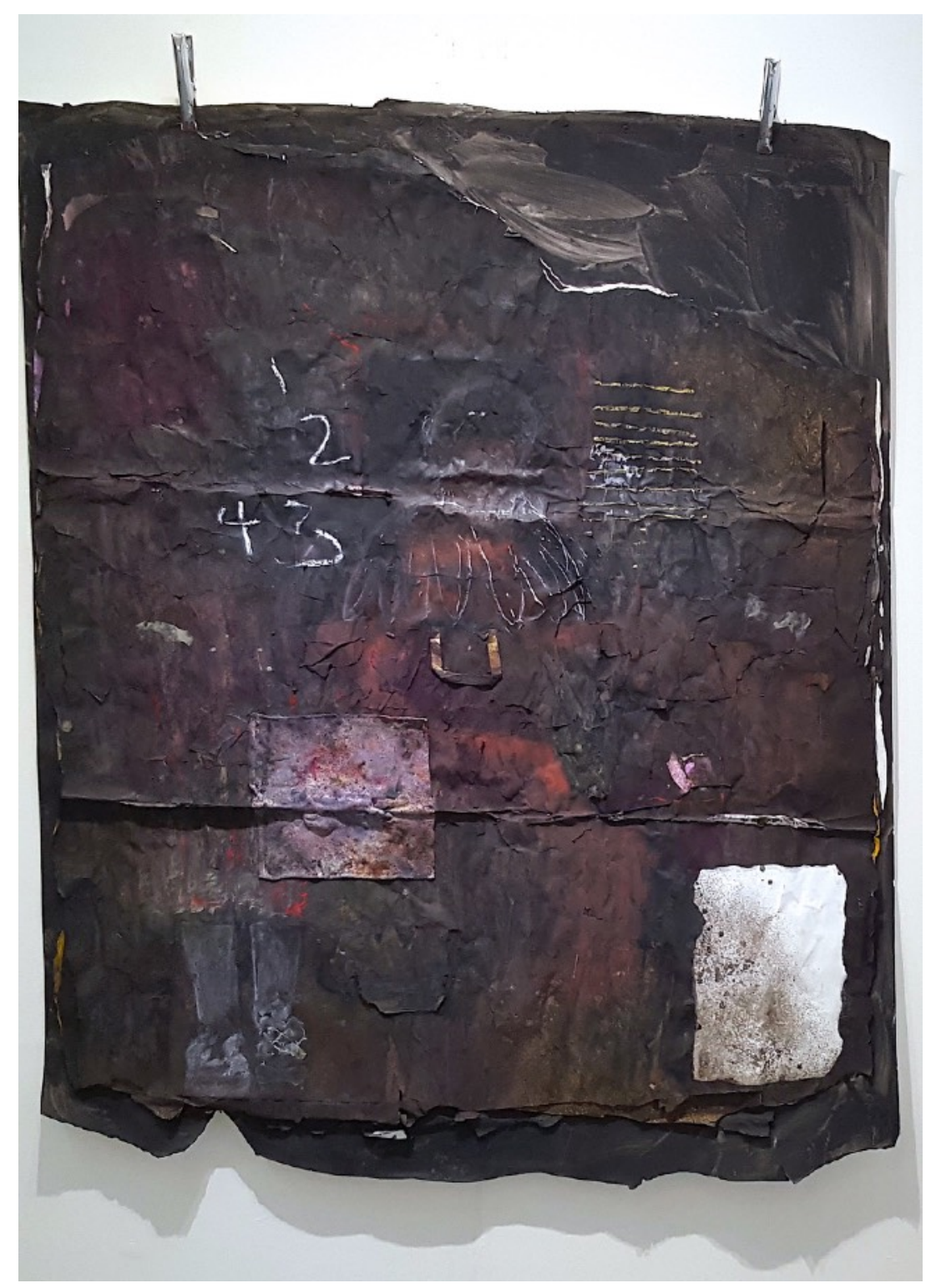

Figure 10. Osaretin Ugiagbe, 1234, metal clamps, multiple layers of paper on paper, oil on rag, charcoal, oil, acrylic ink, print medium, found brown paper bag on paper, $80 \times 59$ inches

sought to bring painting off its pedestal into the real, the everyday. During his time in the United Kingdom his practice increasingly turned away from the trappings of the canon, seeking to break new ground and forge a new way into painting - one that might consider issues of the former British empire, but as a result of his approach, would specifically not be defined by its rules. He achieved this in his methodological approach, developing the methods, materials, and content for the series in ways that allowed him to paint within his own framework, using his own rules. Ugiagbe's current methods include: not working on 
canvas, not displaying his work using traditional cleanly hidden d-rings and wires, instead selecting heavy metal clamps usually found holding together street market stalls to display his paintings. Thinking about how, through practice, he can intervene in the trappings of the canon of traditional Western painting, his media slants toward ink, liquified charcoal, and more minimal paint applications - still painting, but also refuting painting through use of drawing-painting approaches. In 1234, specifically, he also used white chalk, a reference to the classrooms of his youth where teachers made extensive use of chalkboards.

1234 makes a reparative contribution to painting, not just in its turn to the material everyday world of paper bags as canvases and industrial metal clamps signifying that there is room for everyone in these paintings, but also in its use of white chalk which was wielded by the powerful in his childhood and is now, through this painting, wielded at last by his own hand. The empowerment embedded in his dominion over the chalk is significant, as education shapes minds either to think critically or to follow. In the context of growing up in post-colonial Nigeria, then finding himself in the UK, considering what key elements of these cultures needed repair, clearly issues of education and its problematic aspects have risen to the forefront in 1234. Significantly, the backward flowing white chalk text, "1234," also appears over an abstracted intergenerational portrait of his family, working to put a finer point on his commentary about the many generations affected by the colonial, post-colonial, and reconstruction era education systems in Nigeria.

Ugiagbe's work makes a contribution to reparative painting in its materiality and through his command of it as a vehicle to express by showing the power of material to perform an alchemic act, transferring power and borders of the Western cannon of painting and education into the everyday for everyone. 1234 then seems to again return us to bell hooks sage wisdom about art and "... the way in which experiencing art can enhance our understanding of what it means to live as free subjects in an unfree world."39 Maybe, if she wrote about 1234, she too would find it a reparative exit constructed of everyday materials that leads us away from our current circumstances. We should pay close attention here to Ugiagbe's marks as he holds the white chalk, and at last offers a lesson of his own making.

In conclusion, this paper offers a first view of reparative painting theory of, as well as in, practice. It includes detailed case study examples designed to trace the reparative turn in painting beyond a theoretical proposal, through studio and exhibition research contexts, in dialog with an interdisciplinary humanities approach. The methodology incorporated personal practice-led research in painting, curation, studio visit discussions with contemporary painters, and case studies presenting how the selected paintings work in reparative ways. My aim is to offer a practice-led theory which has multifaceted potential to subvert and/or repair damage caused by bias. The painting approaches included offer a multitude of reparative permutations through their production of uplift, imaginative optimistic futures, expression of wounded narratives, examples of transfer and/or realization of power, beauty, rage, recovery from trauma, reclamation, and more. Using an embodied practice-led 
diffractive process to generate constructive exits and formation of agency, this framework has an ambition to offer artists and viewers insight into the potential of a reparative turn to generate release from and repair of the damage that results from subjection. This diffractive approach develops reparative painting theory as seen through and in combination with Sedgwick's concept of reparative reading practice, new materialist conceptions of material aliveness, encounter, and onto-epistemology, art theory that examines art's potential to create social agency, and identity studies. As the many crises of our contemporary reality escalate, constructive approaches to generating individual as well as collective agency, and a psychic/visceral reaching towards an exit from/repair of damaging impacts of systemic racism, misogyny, and homophobia have become increasingly critical. This project answers Sedgwick's call for increased engagement with research using reparative approaches as well as the urgent need for novel paradigms to address issues of social injustice. 


\section{Acknowledgements}

I would like to thank my Mother and Son who have supported and motivated me during the often demanding painting, travel, and work required in pursuit of this elusive aim to develop practice-led reparative painting theory. Thanks also to the teachers who played a part in my development, as well as all the artists whose participation and active engagement in this research process made the project possible. 


\section{BIBLIOGRAPHY}

Barad, Karen. Meeting the Universe Halfway: Quantum Physics and the Entanglement of Matter and Meaning. Durham: Duke University Press, 2006. doi: $\underline{10.1215 / 9780822388128}$

- - - "Posthumanist Performativity: Toward an Understanding of How Matter Comes to Matter." Signs 28, no. 3, Gender and Science: New Issues (Spring 2003): 801-31.

- - - "Transmaterialities: Trans*/Matter/Realities and Queer Political Imaginings." GLQ, A Journal of Lesbian and Gay Studies, Queer Inhumanisms 21, no. 2-3 (2015): 387-422.

Best, Susan. Reparative Aesthetics: Witnessing in Contemporary Art Photography. London: Bloomsbury Academic, 2016.

- - - Visualizing Feeling: Affect and the Feminine Avant-Garde. New York: I. B. Tauris, 2011.

Bickmore, Kate. "Kate Bickmore Artist Website." Accessed January 18, 2019 http:// katebickmore.com

Broadway, Elise. "Elise Broadway Artist Profile Page." Accessed January 18, 2019. https://elisebroadway.com

Butler, Judith. Gender Trouble: Tenth Anniversary Edition. London, GBR: Routledge, 1999.

Coole, Diana H., and Samantha Frost, eds. New Materialisms: Ontology, Agency, and Politics. Durham NC: Duke University Press, 2010.

Elkins, James, ad Harper Montgomery, eds. Beyond the Aesthetic and the AntiAesthetic, The Stone Art Theory Institutes Series, vol. 4. University Park, Pennsylvania: The Pennsylvania State University Press, 2013. 
"English Oxford Living Dictionary." Oxford University Press. Accessed April 23, 2019. https:// en.oxforddictionaries.com

Forrester, Shannon. "Embodying the Reparative Turn: Seeking Agency through Studio Practice in Individual and Collective Contexts. "PhD Dissertation, Royal College of Art, 2018.

- - - "Shannon Forrester Artist Website." Accessed February 20 2020. http:// shannonforrester.com

Geerts, Evelien, and Iris van der Tuin. "From Intersectionality to Interference: Feminist onto-Epistemological Reflections on the Politics of Representation." Women's Studies International Forum 41, no. November-December (2013): 171-178.

Golding, Johnny. "Friendship." In The Edinburgh Companion to Animal Studies, edited by Lynn Turner and Undine Sellbach 262-276. Edinburgh, Scotland: Edinburgh University Press, 2018.

Graw, Isabelle. The Love of Painting: Genealogy of a Success Medium. Berlin: Sternberg Press, 2018. doi: 9783956792519

Halberstam, Jack, and Tavia Nyong'o, eds. "Introduction: Theory in the Wild." The South Atlantic Quarterly, 117, no. 3 Wildness (2018): 453-464.

Hayles, Katherine. Unthought: The Power of the Cognitive Nonconscious. Chicago: The University of Chicago Press, 2017. doi: 10.1080/00393274.2018.1460222

hooks, bell. Art on My Mind : Visual Politics. New York: New Press, 1995. doi: $10.2307 / 1358668$

Jones, Amelia. Seeing Differently: A History and Theory of Identification and the Visual Arts. Abingdon, Oxon England: Routledge, 2012.

Klein, Melanie. Love, Guilt, and Reparation: And Other Works, 1921-1945. New York: Free Press, 1984. 
Laing, Olivia. "Bad Surprises: Conspiracy Theories and Reparative Reading." Frieze 23, no. April (2017). Accessed January 18, 2019. https://frieze.com/article/badsurprises

Mercer, Kobena. "Busy in the Ruins of a Wretched Phantasia." In Frantz Fanon Critical Perspectives 195-218, edited by Anthony C. Alessandrini. London, New York: Routledge, 1999.

Muñoz, José Esteban. Cruising Utopia: The Then and There of Queer Futurity. New York: New York University Press, 2009.

Nielsen, Henrik Kaare. "Discursive Interventions. On the Relationship between the Aesthetic and the Political in Late Modernity." The Nordic Journal of Aesthetics 35 (2008): 46-59.

"Online Dictionary." Merriam-Webster. Accessed April 23, 2019. https://www.merriamwebster.com/dictionary

Pettit, Lydia. "Lydia Pettit Artist Website." Accessed January 18, 2019. https:// lydiapettit.com

Pozniakow, Leon. "Leon Pozniakow Instagram Page." Accessed January 18, 2019. https://www.instagram.com/leonpozniakow/

Pulido, Jhonatan. "Jhonatan Pulido Artist Website." Accessed September 15, 2019. https://jhonatanpulido.co

Reilly, Maura. Curatorial Activism: Towards an Ethics of Curating. New York, USA: Thames \& Hudson, 2018. doi: 99976502754

Sedgwick, Eve Kosofsky. Touching Feeling: Affect, Pedagogy, Performativity. Durham: Duke University Press, 2002.

- - . Touching Feeling: Affect, Pedagogy, Performativity. Durham: Duke University Press, 2003. doi: doi.org/10.1215/9780822384786. 
Segal, Hanna. Introduction to the Work of Melanie Klein. $5^{\text {th }}$ ed. London: H. Karnac Books Ltd., 1988.

Ugiagbe, Osaretin. "Osaretin Ugiagbe Artist Website." Accessed January 25, 2019. https://www.osaretin.com 


\section{ENDNOTES}

1 bell hooks, Art on My Mind: Visual Politics (New York: New Press, 1995), xvi.

2 Melanie Klein, Love, Guilt, and Reparation: And Other Works, 1921-1945, (New York: Free Press, 1984) 123-152. Eve Kosofsky Sedgwick, "Paranoid Reading and Reparative Reading, or You're so Paranoid you Probably Think this Essay is About You," in Touching Feeling: Affect, Pedagogy, Performativity (Durham: Duke University Press, 2003).

3 Susan Best, Reparative Aesthetics: Witnessing in Contemporary Art Photography (London: Bloomsbury Academic, 2016); José Esteban Muñoz, Cruising Utopia: The Then and There of Queer Futurity (New York: New York University Press, 2009).

4 Jack Halberstam and Tavia Nyong'o, eds., "Introduction: Theory in the Wild." The South Atlantic Quarterly 117 no. 3 Wildness, (2018): 453-464. hooks, Art on My Mind.

5 Karen Barad, "Transmaterialities: Trans*/Matter/Realities and Queer Political Imaginings," GLQ, A Journal of Lesbian and Gay Studies, 21, no. 2-3 (2015): 387-422. Karen Barad, "Posthumanist Performativity: Toward an Understanding of How Matter Comes to Matter," Signs 28, no. 3, (2003): 801-831. Karen Barad, Meeting the Universe Halfway: Quantum Physics and the Entanglement of Matter and Meaning (Durham: Duke University Press, 2006). Diana H. Coole and Samantha Frost, eds., New Materialisms: Ontology, Agency, and Politics (Durham NC: Duke University Press, 2010). Johnny Golding, "Friendship," in The Edinburgh Companion to Animal Studies, ed. Lynn Turner and Undine Sellbach (Edinburgh, Scotland: Edinburgh University Press, 2018), 262-276.

6 Sedgwick, Touching Feeling, 150.

7 Best, Reparative Aesthetics, 2. Here Best references anti-aesthetic scholarship in the journal October, https://www.mitpressjournals.org/loi/octo, Sedgwick's, Touching Feeling, and see also James Elkins and Harper Montgomery, eds., Beyond the Aesthetic and the Anti-Aesthetic, (University Park, PA: The Pennsylvania State University Press, 2013) 167.

8 Best Reparative Aesthetics, 3. See also 2015 lecture at Griffith University: https:// www.youtube.com/watch?v=yrAtMeKIYEU

9 Hanna Segal, Introduction to the Work of Melanie Klein (London: H. Karnac Books, 1988), 75. 
10 Sedgwick, Touching Feeling, 128.

11 Segal, Work of Melanie Klein, 75.

12 Barad, Meeting the Universe Halfway, 354.

13 lbid., 384

${ }^{14}$ Isabelle Graw, The Love of Painting: Genealogy of a Success Medium (Berlin: Sternberg Press, 2018), 23, 239, 241. Katherine Hayles, Unthought: The Power of the Cognitive Nonconscious (Chicago ; London: The University of Chicago Press, 2017). In reference to assemblage. Barad, "Posthumanist Performativity," 818. In reference to dynamic.

15 Barad, "Posthumanist Performativity," 802.

${ }^{16}$ Coole and Frost, New Materialisms, 19.

17 Barad, "Posthumanist Performativity."

18 Barad, "Transmaterialities."

19 lbid., 411.

20 lbid., 388.

21 Barad, "Posthumanist Performativity," 802.

${ }^{22}$ Graw, The Love of Painting, 48-58.

23 lbid., 23.

${ }^{24}$ Susan Best, Visualizing Feeling: Affect and the Feminine Avant-Garde (New York: I. B. Tauris, 2011), 8.

25 Halberstam and Nyong'o, "Introduction," 453-463. Referring to the context of wildness.

${ }^{26}$ Best, Reparative Aesthetics, 2.

${ }^{27}$ Kate Bickmore, "Kate Bickmore Artist Website," accessed January 18, 2019. http:// katebickmore.com. 
28 Painting from the Other Side open call application, Kate Bickmore, January 152019 , accessed London, UK.

29 Shannon Forrester, "Shannon Forrester Artist Website," accessed February 20, 2020. http://shannonforrester.com.

30 Shannon Forrester, "Begin," in Embodying the Reparative Turn: Seeking Agency through Studio Practice in Individual and Collective Contexts (PhD dissertation in process, Royal College of Art).

31Jhonatan Pulido, "Jhonatan Pulido Artist Website," accessed September 15, 2019. https://jhonatanpulido.co.

${ }^{32}$ Henrik Kaare Nielsen, "Discursive Interventions. On the Relationship between the Aesthetic and the Political in Late Modernity," The Nordic Journal of Aesthetics 35 (2008), 55.

${ }^{33}$ Lydia Pettit, "Lydia Pettit Artist Website," accessed January 18, 2019. https:// lydiapettit.com.

${ }^{34}$ Elise Broadway, "Elise Broadway Artist Profile Page," accessed January 18, 2019. https://cargocollective.com/elisebroadwayartist/.

35 Leon Pozniakow, "Leon Pozniakow Instagram Page," accessed January 18, 2019. https://www.instagram.com/leonpozniakow/.

${ }^{36}$ Painting from the Other Side open call application, Leon Pozniakow, January 15 2019, accessed London, UK

${ }^{37}$ Kobena Mercer, "Busy in the Ruins of a Wretched Phantasia," in Frantz Fanon Critical Perspectives, ed. Anthony C. Alessandrini (New York: Routledge, 1999), 200.

38 Osaretin Ugiagbe, "Osaretin Ugiagbe Artist Website," accessed January 22, 2019. https://www.osaretin.com.

39 hooks, Art on My Mind, 9. 